\title{
Notes on teaching Chinese to foreign learners
}

\author{
M.A.K. Halliday \\ The University of Sydney, Sydney, Australia
}

\begin{abstract}
Recently there has been considerable discussion over "how to teach Chinese to foreign learners". This article investigates the common problems which Chinese teachers encounter in teaching Chinese to the speakers of English. It points out that (1) for foreign adult learners who are just starting out to learn Chinese, the best teachers are those who speak the same language as their students do rather than native Chinese teachers; (2) the later the students start learning Chinese characters, the faster and easier for them to pick up the language, and hence, Chinese characters should not be introduced at the early stage; and (3) one should aim at achieving phonological accuracy in Chinese.
\end{abstract}

Keywords: Chinese language learning; phonological accuracy; Chinese characters

I first studied Chinese as a teenager; the course began just after my 17th birthday. It was an intensive language course, lasting 20 months. The course was designed and taught in the Chinese Department at the School of Oriental and African Studies, University of London; they were acting on behalf of the British War Office, who needed specialists in various Asian languages to serve in the army, the navy or the air force in the East Asian and West Asian theatres of the war. Chinese was one of the languages for which they sought volunteers within my age group; I had opted for Chinese and had passed the language-specific aptitude test that was a necessary qualification for being accepted on to the course. The course was taught by a team of British and Chinese language teachers, headed by Dr. Walter Simon (who was himself from Germany but had managed to emigrate to Britain just as the Nazis were coming into power). The introductory classes, over the first few months, were all given by Dr. Simon himself, along with another British teacher; the Chinese staff were brought in as we began to master the initial stages of the language. Over time, the classes were very varied; there was structure drill with sentence patterns, always in continuous texts; there was pronunciation, listening and performing (there was a studio with disc recording equipment where we could record our own voices and compare them with the Linguaphone gramophone records - very advanced for the time!); and from time to time, there were dictation classes - a valuable exercise in training listening skills. Later the staff introduced conversation classes, a good idea in principle, but difficult to design and conduct, as they always seem to have been.

We were reading and writing Chinese from the very beginning - but not, of course, in characters. We used GR (Gwoyeu Romatzyh), the system that had been designed by the great Chinese linguist Chao Yuen Ren (Y.R. Chao). This was ideally suited for the foreign learner, because the tones were incorporated into the spelling; that was what helped to make dictation such a useful teaching technique. Characters were not introduced until very late in the first year of the course, which meant that when we did start to study them we learnt them rather quickly, and without too much difficulty, because by that time we were already well acquainted with the language and had reached some measure of fluency. 
We devised some of our own strategies. I soon found that the most effective way of memorizing a new character was to stand in front of blackboard brandishing a piece of chalk and write with the full extension and movement of the arm, preferably at the same time singing a tune to match the rhythm of the strokes (the character for 鬼 goei "ghost", for example, chimes perfectly with the first snatch of Colonel Bogey, a march well known to any British schoolboy). A second trick was to arrange all the characters we were supposed to know into groups ordered according to the phonetic element, as in that little pocket dictionary by the Reverend Soothill, and prepare a set of playing cards with the character on one side and the GR transcription and English gloss on the other. With these you could play a game following the rules of "Happy Families" (remember we had grown up in the 1930s, when children still learnt to play such games with cards).

Meanwhile, of course, we were still mainly working with the GR transcription. We had a large quantity of transcribed reading material, not just from our coursebooks but original Chinese texts such as newspaper articles, essays and short stories. And we were beginning to write simple compositions in Chinese. So at the end of the course, we were reasonably well trained for our war service duties, which turned out to be somewhat varied. The course had been explicitly designed as a general purpose course, not dedicated to any one specific application. I served in Chinese intelligence for a year, but by then the services language courses had considerably expanded and they were short of teachers; so one or two of us were transferred back to Britain to teach the language to other groups of servicemen - in some cases considerably older, and more elevated in rank, than ourselves. In this way, I began my career as a teacher of Chinese, shortly after I had reached the age of 20 .

I was given no training in how to teach, so I went about it in the ways that I had been taught - with one exception, which I will come to in a moment. After all, these had proved reasonably effective. We had been a small class, just 16 of us, all English speakers and all within 1 year of the same age. Altogether, beginning with the almost 2 years of teaching on the armed services courses, when I was myself still in the army, and then later as an assistant lecturer in Chinese at Cambridge, I taught the language for something over 10 years. In the middle of this period, I broke off in order to go and study in China, and there I studied linguistics, under the great Chinese scholar Wang Li. No, he was not teaching me Chinese, though of course I was learning more of the language all the time; he was teaching me linguistics, and that was critical to my later practice as a language teacher - Wang Li's teaching, together with what I subsequently learnt back in England from my other great master J.R. Firth.

And here is the exception I referred to: I taught as I had been taught, except that I also tried to teach the students some grammar. I was very aware that we had been given very little instruction in Chinese grammar, and were largely left to work it out for ourselves. There were so many things in the language that needed to be explained, and the only way to explain them was to locate them within the workings of the grammar. Adult learners need explanations. But they need to be genuine explanations, in terms of the language itself, its underlying patterns and principles, not the fake explanations so often offered in terms of stereotypic features of the culture, derived from stories of Chineseness told by foreigners or by the Chinese themselves.

I am not advocating grammar classes - lessons where grammar becomes the primary content. Grammar is there to be called upon when needed, for providing generalizations and explaining things that the learners find difficult or puzzling. And it has its limits: not everything in a language can be illuminated by being placed in some functional context. But a great deal of it can, and for the adult learner this can be enlightening. So for the 
teacher, an understanding of the grammar is a valuable resource that may be called on at any time, not a distinct component of the course. With this in mind, let me suggest three factors which can help foreign learners become more successful in their learning of Chinese:

(1) Beginners should preferably be taught by speakers of their own language (e.g. English), not by native speakers of Chinese. (I am assuming the learners are adolescents or adults; this does not apply to young children, who can well be taught by native speakers from the start.) In other words, mature beginners are best taught by people who have learnt the language from the outside as they are doing themselves. Native speakers come in later, when the students have mastered the essentials of the learning task and can recognize and take advantage of the native speakers' superior knowledge.

(2) Chinese characters should not be introduced from the start, preferably not till the end of the first year of the course. The general principle is that the longer you postpone facing the students with characters, the more easily and more quickly they will learn them. This means that large amounts of interesting reading material need to be made available to them in transcription. Nowadays this almost inevitably means in Hanyu Pinyin, and this poses a problem because although Pinyin is an excellent system for the purpose for which it was devised (essentially, the needs of the Chinese themselves: teaching standard Chinese to dialect speakers, use in dictionaries and other reference books, street and station names and other displays for the benefit of visitors), it is not ideal for foreigners learning the language. There is not enough redundancy in it, and it does not spell out the tones. (Tone is indicated by accents, and these are usually left out, as I found when I first started to teach using Pinyin.) Various compromise systems have been devised over recent decades, but none has been widely adopted, and in my view, none had all the merits of GR.

(3) Much more attention should be given to accurate training in phonetics - which in turn needs to be based on an understanding of Mandarin phonology. Standard Chinese, or Putonghua, is a variety of Mandarin, and Mandarin phonology follows certain well-defined prosodic (non-phonemic) principles in the composition of the syllable: an opening state, a closing state, with a trajectory between the two. The trajectory is "coloured" by the two outer postures, and it includes the tone. Teachers are often asked the question: Is the tone really that important? The answer is no, provided you get everything else exactly right. A native speaker of Chinese, listening to a foreigner talking the language, can cope with quite a lot of deviation from the familiar patterns of meaning, of lexicogrammar and of sound. Such deviation is typically spread around all these features, but there can be a trade-off - the sound may be severely distorted, as with a defective telephone connection, but if the meaning and the wording are not deviant, the message will still come through. If they are, however - if the speaker has some speech disorder, or if it is a foreigner talking - the distortion in the sound may be critical. So if foreigners get the tones right, as part of the overall sound pattern, they can get away with quite a lot of "un-Chinese" effects in their meanings and in their grammar and vocabulary.

Like (I suspect) many foreign language teachers, I began by assuming that every learner learns in the same way - in other ways, I simply hadn't thought about it. But this of 
course is an illusion, and once it has been dispelled you become dismayed by the thought that if you are faced with a class of 25 students, they have 25 different ways of learning. Luckily this is also an illusion. What I found, in fact, in teaching Chinese, was that there were a few parameters along which learners would vary, so each individual's way was in some combination of where he/she was located on each of these four scales. With any one of them, the learner might lie towards one end or the other, or just somewhere around the middle. The four scales of variation seemed to be somewhat like the following:

(1) By ear or by eye. This is perhaps the most obvious source of variation: some learners learn more by listening (and speaking), and others learn more by reading (and writing).

(2) By performance or by reflection. Some learners learn more by doing - trying out their ability in the language; others learn more by thinking - planning before they perform.

(3) By content or by expression. Some learners focus more on the meaning; others focus more, or at least as much, on the sound and perhaps also the sight.

(4) By principle or by example. Some learners work from the top down, deriving instances from generalizations; others work from the bottom up, finding out patterns for themselves.

Where would I locate myself along these various scales? I am an extreme ear-learner - I cannot learn a language, especially its vocabulary, from reading it, only by listening and speaking. On performance versus reflection, I am some somewhere about the middle. On content versus expression, as a learner I tend rather towards the expression end - which is perhaps why I became a grammarian, to redress the balance. As regards learning by principle or by example, here I find I am always "shunting", moving alternately in one direction or the other.

I must admit that I never studied learning theory, nor did I pursue these thoughts any further after I switched from teaching Chinese to teaching linguistics. I imagine that this kind of variation among learners will have been fully documented and calibrated with other factors such as personality, visual and auditory capacity and so forth, but this I have not explored.

It helps, I think, for the teacher to be aware of these variables; or at least of the fact that there will be this kind of variation among individual learners: there may be other factors to take account of as well. We need as far as possible to provide for a mixed population, in the design of the course and in pedagogical method and practice. With half a century of technological innovations, from the phonetics lab (now "speech science") to the language lab to the whole battery of electronic resources from the computerized classroom to the virtual learning environment, this can in principle all be managed by the learners themselves - provided they know about the options, and have access to them; and provided they are aware of their own predilections and needs, which they have to find out for themselves. Meanwhile, although people have been predicting the demise of the language teacher ever since "programmed learning" was touted in the 1960s, when it comes to teaching Chinese to foreign learners the demand for teachers shows no sign of slackening off.

So how are the teachers being trained? The great majority of them are still native speakers of Chinese; are they being trained to look at Chinese through the eyes of a foreign learner - to see what Chinese looks like from the outside? The problem is that 
they may come equipped with a baggage of myths about the Chinese language, and Chinese culture, which simply make the learning task more difficult for the "western" (i.e. North and South American, African, Australian, European or South and South-west Asian) learner.

Probably every community has myths about its language, including about why it's easy, or else virtually impossible, for any foreigner to learn. Many of the Chinese myths arise out of the nature of the script, which is based on the morpheme, not on the phoneme or the syllable. The first essential for any Chinese teaching their language to foreigners is that they should become totally at home with the language written in a phonemic script to be able to read and write Pinyin (or whatever transcription is being used) not only accurately but also fluently. This will blow away much of the mythology in one short puff of breath, as they find that their language is still there - it hasn't disappeared, or even changed, just because it no longer looks the way it did. ${ }^{1}$

But here we begin to move beyond a concern with sensible teaching practice, to issues that may seem somewhat remote but that do play a large part in determining how effective these practices are going to be. The issues are complex, but, then, learning and teaching are highly complex processes. Every language is unique, but none is "more unique" than any other. Many languages have one or two exotic, or "extreme", features, but the overall picture is that each language is some particular combination of a set of very general properties. And these often show up in regional groupings: languages that live close together, even if they have not had the same history, tend to grow alike. Chinese is a rather typical East Asian language, just as English is rather typical West European one. They both have some slightly exotic features (serial tense in English and completive phase in Chinese are both more elaborated than in other similar languages), but these are not, in general, part of the popular image, which is rather more simplistic than this.

For example, teachers used to maintain that Chinese "had no grammar" because the words did not inflect morphologically; I don't think one still hears this today, but it is often said that Chinese dose not display clear-cut syntactic categories - that it is more "fluid" or "flexible" than other languages. It is true that morphemes are not distributed into classes, but words are, including words consisting of just one morpheme, and these classes are reasonably clear-cut - as much as grammatical categories ever are (they are inherently indeterminate, or "fuzzy", in any language). For example, English water, Chinese shǔ 水, and English stone, Chinese shitou 石头, are nouns; English drink, Chinese $h \bar{e}$ 喝, and English run, Chinese păo 跑, are verbs. In English, these are readily transcategorized, as in have my flowers been watered?, the traitor was stoned by the crowd, I've spilt my drink, you can have the run of the house. In Chinese, the equivalents are not possible: shŭ and shitou can't be verbs, $h \bar{e}$ and păo can't be nouns (you don't say wŏde huā shuĭhăole méiyŏu? wŏ bă wŏde hē pèngdăole). I'm not suggesting that the discrepancy always works that way - we will find cases where a word can be transcategorized in Chinese but not in English; the point is that neither language is measurably more indeterminate than the other.

It has to be said that linguistics does not yet offer, at this time, the help that is really needed. It is nearly a hundred years since Edward Sapir observed that every language had "a certain cut", its unique blend of semantic, lexicogrammatical and phonological styles, and its "characterology" in Prague School terms. We ought to be able to model this for teachers, but as yet we can't. ${ }^{2}$ It is highly complex and highly abstract - the semiotic analogue of the interlocking material forces of a very sophisticated machine, a musical instrument, or a species of living organism - the essential catness of a cat, for example. This is not a kind of ideal harmony; rather it is a tension among opposing, co-operating 
and tangential forces, with every component the product of its own evolutionary history. Even where that history is known - and quite a lot is known, of the history of Chinese, as also of English - it is not accessible in a form that language teachers could be expected to interpret and build in to their teaching practice. You don't teach anything by simply tracking it along the route by which it evolved.

So that part of the edifice is missing. But we can still do a lot towards promoting the more effective teaching of Chinese, provided we re-examine and re-evaluate the whole ethos of Chinese language studies in relation to current political and intercultural realities (McDonald 2011). In some way, this corresponds quite well to the background in which I started, of British-Chinese collaboration in the war effort, and perhaps encapsulated for the modern reader in Joseph Needham's monumental "Science and Civilisation in China" (I talked with Needham often in the early years of that great enterprise) - rather better, perhaps, than to some of the thinking that has prevailed in Chinese language teaching in the meantime.

\section{Acknowledgement}

'Notes on teaching Chinese to foreign learners,' from Foreign Languages in China 2012(4), Beijing: Higher Education Press, 2012, pages 4-8. Reprinted with the permission of Higher Education Press.

\section{Notes}

1. In other words, it makes no difference to the language how it is written down: the writing system does not affect its structure or its evolution. Since throughout most of the history of literate societies no more than about $20 \%$ of males were literate, and the proportion of literate females was even lower (and it is the females from whom the children learn their first language), it would be surprising if the script did make any difference. On the other hand, now that in many societies almost all adults are able to read and write, and China is one of them, the characters may well begin to have an effect; because they distinguish different morphemes, including many that are pronounced alike, the likely effect would be to increase the distinction between the written and the spoken language.

2. There have of course been numerous outlines, "thumbnail sketches" and the like, both of wellknown and of less well-known languages, presenting some profile of the language or of one particular part of it. These can be very valuable, in various contexts including that of foreign language learning. But they are not the same thing as a "characterology", which would set out to present an integrated picture of the unique character of the language.

\section{Notes on contributor}

M.A.K. Halliday is Emeritus Professor in Linguistics, University of Sydney, Australia.

\section{Reference}

McDonald, E. 2011. Learning Chinese, Turning Chinese: Challenges to Becoming a Sinophone in a Globalised World. Abingdon, UK: Routledge. 